\title{
The Lucretian Puzzle and the Nature of Time
}

\author{
Jens Johansson ${ }^{1}$
}

Received: 13 December 2016/ Accepted: 31 January 2017/Published online: 9 February 2017

(C) The Author(s) 2017. This article is published with open access at Springerlink.com

\begin{abstract}
If a person's death is bad for him for the reason that he would have otherwise been intrinsically better off, as the Deprivation Approach says, does it not follow that his prenatal nonexistence is bad for him as well? Recently, it has been suggested that the "A-theory" of time can be used to support a negative answer to this question. In this paper, I raise some problems for this approach.
\end{abstract}

Keywords Death · Deprivation approach · Lucretian puzzle

\section{Introduction}

According to the Deprivation Approach to the badness of death, in many cases death is overall bad for the one who dies; and when it is, it is bad for him because, and to the extent that, he would have been on balance intrinsically better off if it had not occurred. (Bradley 2009; Feldman 1991; Luper 2009) The term "overall" is there for two reasons. First, deprivationists do not primarily aim to capture death's intrinsic value (if any) for the one who dies, or its extrinsic value for him, but rather a value that combines death's intrinsic and extrinsic value for him. Second, the relevant sort of value is supposed to combine death's entire intrinsic and extrinsic value for him. The claim is thus not that a person's death can be bad for him in a certain specific respect, for instance by depriving him of life's most meaningful activities, or by making trouble for him at one particular time. The view is, instead, concerned with death's "all things considered" badness for the victim.

Despite being about something appalling, the Deprivation Approach is appealing. In particular, in addition to giving the intuitively correct result in lots of cases in

Jens Johansson

jens.johansson@filosofi.uu.se

1 Department of Philosophy, Uppsala University, Box 627, 75126 Uppsala, Sweden 
which a person dies-for instance, it yields that death is typically a serious misfortune for a healthy thirty-year-old, but not so much for a permanently ill eighty-year-old - it is congenial with plausible judgments about non-death-related evils. Typically, for example, it is overall bad for a person to be hit by a car, or to catch a disease, or to be drugged into unconsciousness; and it is attractive to say that this is precisely because he would have otherwise been on balance intrinsically better off. A mark in favor of the Deprivation Approach, then, is that it makes death relevantly similar to other overall bad things.

In this context, however, the "Lucretian puzzle" arises. ${ }^{1}$ If death is an evil for the reason offered by the Deprivation Approach, then it seems that prenatal nonexistence-that is, its not being the case that the person comes into existence earlier and thereby lives a longer life-must often be an evil, too. For, in many cases, if the person had come into existence earlier and thereby lived a longer life, then he would have been on balance intrinsically better off (indeed, much better off) than he actually is. The problem is that, intuitively, a person's prenatal nonexistence is not bad (let alone very bad) for him. Of course, this does not show that deprivationists are wrong in taking a person's death to be bad for him, but it suggests that, if it is, their explanation of this fact is unsatisfactory.

Recently, a number of authors have argued that certain views of the nature of time have a significant bearing on this and related puzzles. (Deng 2015; Robson 2014; see also Le Poidevin 1996) Specifically, it has been argued that some versions of the "A-theory"-according to which there is an absolutely present timeprovide deprivationists with a promising response to the Lucretian. I shall devote most of my discussion to Natalja Deng's suggestion, according to which, on some suitable A-theoretic views, a person's death deprives him of intrinsic goods, whereas his prenatal nonexistence does not (Sects. 2-5). However, I shall also discuss Jon Robson's approach, which is based on the A-theoretic view that future things, unlike past and present things, do not exist (Sect. 6).

\section{Deng's Approach}

We can all agree that 2017 is later than 2005, and that Donald Trump's presidential term occurs later than his and Melania Trump's wedding. We can all agree that 2017 as well as 2005 is present relative to itself. And we can all agree that my utterance of "Donald Trump is now President" is simultaneous with a portion of his presidential term, just as the priest's utterance of "You are now husband and wife" is simultaneous with a portion of the Trumps' marriage. But we do not all agree on whether "tenseless" facts like these are all there is to temporal reality. According to the B-theory of time, they are. In particular, no time is absolutely present; every time is simply present relative to itself (just as no place is absolutely here; every place is simply here relative to itself). According to the A-theory, by contrast, there

\footnotetext{
1 So-called as it is based on some suggestive remarks by Lucretius (1940: 134). For a recent debatemuch of which has taken place in The Journal of Ethics-on the response suggested in Brueckner and Fischer (1986), see Cyr (2014, 2016), Feldman (2013), Fischer and Brueckner (2013, 2014a, b, c), Johansson (2013, 2014a, b, 2016) and Purves (2015).
} 
are irreducibly tensed facts; in particular, there is an absolutely present time. As Deng points out, it is natural to think that the A-theory, unlike the B-theory, allows the passage of time to be an objective feature of the world. (Deng 2015: 425; contrast Deng 2012) After all, the present moment has not always been present, and will soon enough cease to be so; similarly, on the A-theory, not only does a persisting thing have an absolute age, its absolute age steadily becomes higher.

Deng claims that a process "as metaphysically fundamental as A-theoretic passage" can be expected to have significant axiological consequences as well. (Deng 2015: 425) In particular, she suggests, it lends credibility to the view that some present and future events, though no past events, are intrinsically good or bad for a person. As is common in the debate on the Lucretian puzzle, Deng assumes a simple hedonistic axiology; this is strategically desirable, since such an axiology is what underlies many criticisms of the Deprivation Approach, especially from those who deny that death is an evil. (Epicurus 1940) On this simple hedonistic view, all basic bearers of intrinsic goodness for a person are experiences of pleasure, and all basic bearers of intrinsic badness for him are experiences of pain. The relevant A-theory-based view then says that the basic bearers of intrinsic goodness for a person are his own present and future experiences of pleasure, whereas the basic bearers of intrinsic badness for him are his own present and future experiences of pain. Of course, each of his past experiences of pleasure or pain once was intrinsically good or bad for him, but it lost its intrinsic value for him once it ceased to be present.

This view, Deng suggests, provides proponents of the Deprivation Approach with a promising solution to the Lucretian puzzle. For whereas a person's death deprives him of future experiences of pleasure, which on this view are intrinsically good for him, his prenatal nonexistence only deprives him of past experiences of pleasure, which on this view are not intrinsically good for him. ${ }^{2}$ Thus, the deprivationist explanation of the evil of death does not, after all, commit its defenders to the evil of prenatal nonexistence.

For the more technically inclined, Deng takes "the (current) intrinsic value of a [possible] world $w$ for $s$ " to be "the amount of present or future pleasure $s$ experiences in that world, minus the amount of present or future pain $s$ experiences in that world." (Deng 2015: 425) The proposed principle is then:

The (current) overall value for $s$, of a state of affairs $p=$ the (current) intrinsic value for $s$ of the closest $p$-world, minus the (current) intrinsic value for $s$ of the closest not-p-world. (Deng 2015: 426)

Given this principle, the overall value for a currently living person of his death is negative, assuming that, in the closest world in which his death does not occur, he receives a greater amount of pleasure minus pain at and after (what is in fact) the present time than he does in the actual world at and after the present time. By contrast, the overall value for him of his prenatal nonexistence is not negative, for in the closest world in which he starts to exist earlier and thereby gets a longer life, he

\footnotetext{
${ }^{2}$ I am using "deprive" in a value-neutral sense; thus, that something deprives someone of something does not entail that it is bad for him.
} 
does not receive a greater amount of pleasure minus pain at and after (what is in fact) the present time than he does in the actual world at and after the present time.

Deng emphasizes the difference between her approach and a related view. On the related view, a person's death and prenatal nonexistence are both bad for him, but whereas it is rational for him to have negative attitudes toward his death (as it deprives him of future pleasure), it is not rational for him to have negative attitudes toward his prenatal nonexistence (as it only deprives him of past pleasure). (cf. Fischer and Brueckner 2014a: 8-9) According to Deng, it is preferable not to have to bite the bullet and accept that a person's prenatal nonexistence is, in fact, bad for him. In contrast to the related view, her view leaves that bullet unbitten.

As Deng notes, her proposal does not yield that it will always be the case that a person's death is bad for him: there will be a point after his death at which he would have no more pleasure in store, even if his actual death had not occurred (for instance, because he would have died a later death by then). Similarly, Deng's proposal does not yield that it has never been the case that the person's prenatal nonexistence is bad for him: the pleasure of which his prenatal nonexistence deprives him has not always been past. In other words, Deng's approach does not yield an eternal value asymmetry between death and prenatal nonexistence. But the important thing, she argues, is that her view allows us to say that a (currently living) person's death, unlike his prenatal nonexistence, is bad for him.

\section{Metaphysical Versus Axiological Asymmetry}

Is the A-theory true? In the present context, this is not an appropriate question. Deng, who is not herself an A-theorist, claims only that if some suitable version of the A-theory is true, then it offers deprivationists a promising response to the Lucretian puzzle. Naturally, this is more interesting if the relevant A-theoretic view is true than if it is false, but it is interesting enough so long as that view is, at least, not very unlikely to be true. Here is a more appropriate question: Why believe that the A-theory (in some suitable version), if true, gives rise to an axiological asymmetry between past and future pleasure?

The most straightforward way of ruling out the intrinsic value of past experiences of pleasure would be to deny their existence. This is what the most popular version of the A-theory does: according to "presentism", present things exist, whereas past and future things do not. But of course, if presentism rules out the intrinsic value of past pleasure for this reason, then it also rules out the intrinsic value of future pleasure. Indeed, if the "growing block" view-the A-theoretic view that past and present things exist, whereas future things do not-is true (as Robson's approach assumes; see Sect. 6), the same consideration rules out the intrinsic value of future pleasure, but not the intrinsic value of past and present pleasure. This is the reverse of what Deng needs. As she points out, the A-theoretic view that corresponds ontologically to her proposed axiology is, instead, the "shrinking block" view, on which present and future things exist, whereas past things do not. But as she also indicates, this view is something of an outlier in the A-theoretic family-one that presumably fails to satisfy our "not very unlikely to be true" desideratum. 
However, Deng suggests that other A-theoretic views might be suitable for her purposes. Specifically, on the "moving spotlight" view, although past, present, and future things all exist, one time is metaphysically special by being absolutely present. ${ }^{3}$ Present events are those that are in the spotlight of the present, although they have of course been future, and will become past. Future events are continuously moving toward the spotlight, whereas past events are moving further and further away from it. (Or, if you like: the spotlight is continuously moving away from past events and toward future events.) In saying this, the moving spotlight view yields a kind of metaphysical—though not ontological—asymmetry between past and future events. Does it also yield the axiological asymmetry that Deng proposes? Deng thinks so:

This difference ... provides a rationale for assigning objective intrinsic value only to present and future experiences. Those are the experiences still to come, the ones we rightly look forward to or dread. The passage of time, the moving of the spotlight, annihilates this intrinsic value even though it does not annihilate the events themselves. (Deng 2015: 429-430)

However, there is not much of an argument here. It is not clear to me why an experience of pleasure's moving toward the spotlight, as opposed to moving away from it, should be taken to indicate that it is intrinsically good for the subject. Is this idea really more plausible than the idea that someone's experience of pleasure is intrinsically good for him when and only when it is in the spotlight? Is it more plausible than the idea that someone's experience of pleasure is always intrinsically good for him just in case it has been, is, or will be in the spotlight? For that matter, is it more plausible than the reverse idea that, although an experience of pleasure is not intrinsically good for the subject until it enters the spotlight, once it has been in the spotlight, it continues to be intrinsically good for him (much as, for example, although an individual is not dead until his biological processes have ceased to function, once they have done so, he continues to be dead)? Perhaps the answer is Yes to all these questions, but that remains to be shown.

Note, furthermore, that it seems clear that a person's future pleasure is not intrinsically better for him now than it used to be; someone's 2018 pleasure is not intrinsically better for him in 2017 than it was in 2016. However, if experiences of pleasure that move toward the spotlight are intrinsically good for the subject, whereas those that move away from it are not, then it needs to be explained why a future experience of pleasure is not also intrinsically better the closer it gets to the spotlight. After all, if people who are walking forward toward a nonmetaphorical spotlight have their faces lit, whereas those who are walking forward away from it do not, then presumably a person walking forward toward the spotlight has his face more lit the closer he gets to the spotlight.

It may be argued that these doubts are misplaced. For, it may be suggested, it is simply an intuitively plausible claim that a person's present and future experiences of pleasure, unlike his past experiences of pleasure, are intrinsically good for himand absolutely so, as opposed to being merely intrinsically good for him relative to

\footnotetext{
3 She also mentions a "thinning tree" view (Deng 2015: 430), which I shall not discuss separately.
} 
some time. While the moving spotlight view might not exactly provide any positive reason to accept this claim, no such reason is needed (aside from the claim's intuitive appeal). What matters is only that our theory of time allows the claim to be true; and the moving spotlight view does this, as it takes events to be absolutely past, present, and future. By contrast, B-theorists can at most say that those of a person's experiences of pleasure that are present or future relative to a given time are intrinsically good for him relative to that time, whereas those that are past relative to that time are not.

I doubt whether the claim in question is intuitively plausible. Be that as it may, we shall now turn to some problems for it, ones that are largely independent of the A-theory/B-theory controversy.

\section{Past Pleasure}

Again, on the Dengian axiology, a person's past experiences of pleasure are irrelevant to the intrinsic value of a possible world for him, and therefore to an event's overall value for him. Here are two critical points about this.

First, in Sect. 1, I said that one virtue of the Deprivation Approach is that it congenial with attractive judgments about non-death-related evils, such as being hit by a car, catching a disease, or being drugged into unconsciousness. Deng's approach seems to sacrifice at least some of this virtue. For with regard to events that no longer affect the person's receipt of pleasure and pain, Deng's approach is congenial with unattractive judgments about non-death-related evils. Suppose, for instance, that a currently living person was hit by a car in the past, and that he would have otherwise occupied a much higher hedonic level in the years that followed, but at every present or future time occupies the same hedonic level as he would have done at that time without the accident. It is, of course, very plausible to deny that the person's present and future momentary well-being levels are affected by the accident: he is right now, and will continue to be, no less intrinsically well off than he would have been if the accident had not occurred. This is, then, one notable respect in which the car accident is not bad for him. But recall, from Sect. 1, that overall badness for a person-which is what the Deprivation Approach is concerned with-involves all things considered badness for him; and it does not seem attractive to deny, as the Dengian will need to do, that the car accident is all things considered bad for the person. Naturally, even on Deng's approach, the car accident has been overall bad for the person (namely, when the pleasure of which it deprives the person was future); but as indicated earlier, the same holds for prenatal nonexistence as well. Intuitively, the car accident, like his death, is a serious misfortune for him in a way that his prenatal nonexistence is not. It belongs in the same group as death and other overall evils, not in the same group as prenatal nonexistence and other overall non-evils.

Second, Deng's approach is difficult to reconcile with the rationality of certain attitudes toward past experiences. Compare two possible scenarios: in the first one, the person has had a long and pleasant life, but because he is about to die he has only a small amount of pleasure (and no pain) in store; in the second possible 
scenario, he has had a long and painful life, and is about to die, but has slightly more pleasure in store than in the first scenario (and no pain). It seems to be clearly rationally permissible for the person's friends and family to prefer, now, for his own sake, the first scenario to the second. Surely rationality does not require indifference toward the past pleasure and pain of our loved ones, or regarding their past pleasure and pain as lexically less important than their present and future pleasure and pain. ${ }^{4}$ However, if the first scenario were intrinsically worse for the person than the second scenario-as Deng's approach yields - it is hard to see why this preference for the first scenario would be rationally permissible. In saying this, we need not deny that the person's friends and family are rationally permitted to prefer, for his sake, the scenario that is intrinsically worse for him. For it may be argued that a strong form of "future bias" is rationally permissible here, so that the person's friends and family are also rationally permitted to prefer the second scenario (as his future contains more pleasure there), even if it is intrinsically worse for him. In this way, what is intrinsically best for the person might come apart from what they are rationally permitted to prefer for his sake. However, this does not mean that these two factors can come apart in just any way. In particular, the appeal to future bias cannot give us any reason to think that, although the preference for the first scenario is rationally permissible, the second scenario is nevertheless intrinsically better for the person. For the preference for the first scenario is evidently not due to any future bias (again, the person's future contains less pleasure there). It might be suggested, instead, that the current preference for the first scenario is rationally permissible because the first scenario once was intrinsically much better for the person than the second scenario (for example, at a time when all the relevant experiences were in the future). However, if the past intrinsic value of a scenario is relevant to the rationality of current preferences, why think that it is irrelevant to current overall value (as the Dengian view says)? That would be an odd combination of views.

\section{Being Worse Off}

Recall that, on the Deprivation Approach, in cases where death is overall bad for the one who dies, it is overall bad for him because he would have otherwise been on balance intrinsically better off. The Lucretian points out that if this is the explanation, then there are also many cases in which the person's prenatal nonexistence is overall bad for him. Deprivationists who, like Deng, want to avoid that consequence need to show that, whereas a person's death makes him on balance intrinsically worse off (in many cases), his prenatal nonexistence does not. In order for Deng's proposal to have any significant bearing on the Lucretian puzzle, it is not enough to deliver just any sort of value asymmetry between death and prenatal nonexistence; it needs to deliver this particular result. Does it?

\footnotetext{
4 This should be accepted even by those who believe that such an attitude is rationally required towards one's own past pleasure and pain. As is often observed, there is an intuitive difference, with regard to the rationality of temporal partiality, between the first-person and the third-person case.
} 
It may be instructive to begin with a view that, if true, would be promising in this regard. Note first that, plausibly, if an event makes a person on balance intrinsically worse off by depriving him of pleasure, then that pleasure would be intrinsically good for him at the time at which he would receive it. Now consider the view that this condition is satisfied by the pleasure of which a currently living person's death deprives him, but, surprisingly enough, not by the pleasure of which his prenatal nonexistence deprives him. For, on this view, although someone's future experiences of pleasure will be intrinsically good for him when their time comes, his past experiences of pleasure were not intrinsically good for him even while he had them. While this view seems absurd (how could past and future pleasure differ in this way?), it would, if true, support the thesis that the person's death, unlike his prenatal nonexistence, makes him on balance intrinsically worse off. By contrast, Deng's suggestion is not absurd; her claim is only that the pleasure of which the person's death deprives him, unlike the pleasure of which his prenatal nonexistence deprives him, would be intrinsically good for him now (in addition to being intrinsically good for him when he would receive it, just like all his pleasure). But in return, it is more unclear in what way her claim is supposed to have any relevance to the person's well-being-to how intrinsically well off he is in the respective possible worlds.

Admittedly, on the most natural understanding of the claim, it does have such relevance. For on the most natural understanding of the claim, the pleasure of which the person's death deprives him, unlike the pleasure of which his prenatal nonexistence deprives him, would contribute positively to how intrinsically well off he is right now. However, the most natural understanding of the claim makes the claim implausible. (Johansson 2013: 58-59) For one thing, it is doubtful whether how intrinsically well off a person is at a certain time can depend, even in part, on what happens later-and especially on a hedonistic axiology. For another, if a person's future but not past pleasure contributes positively to how intrinsically well off he is now, then, implausibly, a happy person who receives an equal amount of pleasure every day gets increasingly worse off, as more and more of his experiences of pleasure move into the past. Deng is well aware of problems like these (Deng 2015: 428), and consequently distances herself from the thesis that a person's future experiences affect how intrinsically well off he is now.

By doing this, however, she appears to me to also distance herself too much from the thesis that the person's future death, unlike his prenatal nonexistence, makes him on balance intrinsically worse off. Plausibly, in order for the alleged fact that the person's future pleasure is intrinsically good for him now to make a difference to how intrinsically well off he is on balance, it has to make a difference to how intrinsically well off he is at some moment. (At least this is reasonable if we assume, with Deng, a hedonistic axiology. On some non-hedonistic views, how intrinsically well off someone is on balance is not solely dependent on how intrinsically well off he is at moments. This is usually because, on those views, some things that help determine how intrinsically well off a person is on balance-e.g., the "shape" of his life-cannot be located at any moment. By contrast, however, pleasure can be located at moments). As just noted, a person's future pleasure is not intrinsically good for him now in any way that makes a difference for how intrinsically well off 
he is now; nor does it seem to make a difference for how intrinsically well off he is at any other time at which he does not receive the pleasure. As for the time at which he does receive the pleasure, is not all that matters to how intrinsically well off he is at that time what intrinsic value that pleasure will have for him then (aside from, of course, the intrinsic value that the pain he experiences then has for him then)? The current intrinsic value of that future pleasure seems neither here nor there.

A Dengian might suggest that the person's death (unlike his prenatal nonexistence) makes him on balance intrinsically worse off simply in the sense that the current intrinsic value for the person of the closest possible world in which his death does not occur (unlike that of the closest possible world in which his prenatal nonexistence does not occur) is greater than the current intrinsic value of the actual world. (cf. Deng 2015: 428). But this gets things backward. The notion of a world's intrinsic value for the person is of interest in the present discussion only if it captures the notion of well-being, or being intrinsically well or badly off; surely the latter notion is prior to the former (Feit 2016: 19) We can explicate the notion of a world's intrinsic value for the person in terms of his being intrinsically well or badly off-not the other way around.

Even if Deng's view is true, then, it is questionable whether future pleasure, unlike past pleasure, is intrinsically good for the subject now in any way that makes a difference to how intrinsically well off he is. As a result, it is questionable whether Deng's view has any real bearing on the Lucretian puzzle.

\section{Robson's Approach}

As I mentioned in Sects. 1 and 3, Robson (unlike Deng) appeals to the growing block view, the A-theoretic view that past and present things exist, whereas future things do not. According to Robson, the growing block view helps us deal with a number of important challenges to the thesis that death, in many cases, is bad for the deceased. One of these challenges, he says, is the Lucretian question of how it can be true that a person's death will be bad for him although his prenatal nonexistence was not bad for him.

Robson emphasizes that on the growing block view, dead people exist. True, if an individual has died, he is not located at the present moment, and in this sense he fails to exist now. However, he nonetheless exists simpliciter; he is still a part of reality; presumably he exemplifies genuine properties, such as being dead. By contrast, if an individual's life has not yet begun, not only does he fail to exist now, he fails to exist in any sense whatsoever; he has "no more ontological status than leprechauns or the golden mountain." (Robson 2014: 914) Alternatively put, whereas there are individuals whose entire lives are behind them, there are no individuals whose entire lives are before them. Further, Robson states that "it seems obvious that one must exist, in one form or another, in order to suffer any evil." (Robson 2014: 914) Thus, the growing block theorist can plausibly hold that a currently living person's death will be bad for him when his life is over while denying that his prenatal nonexistence was bad for him when his life had not yet begun. 
According to Robson, this proposal also helps us deal with a related puzzle, namely, "why at the present moment I have reason to lament the fact that I will cease to exist upon my death but no reason to lament the fact I did not exist prior to my birth." (Robson 2014: 914) For, Robson suggests, a currently living person has reason to lament his future death only if it will be bad for him when his life is over; similarly, he has reason to lament his prenatal nonexistence only if is was bad for him before his life began. On the above proposal, the first condition may well be satisfied, but the second one is not.

Whatever our verdict on Robson's solutions to the two puzzles on which he concentrates, however, those solutions do not really help the deprivationist in responding to the arguably more important puzzle with which we began (Sect. 1), and which is the one that concerns Deng and many others. To repeat, the deprivationist claims that a person's death, in many cases, is bad for him, because, in many cases, he would have been on balance better off without it. The Lucretian challenge is then that if this is the case, then, implausibly, the person's prenatal nonexistence is bad for him as well. ${ }^{5}$ Saying that the person's prenatal nonexistence was not bad for him before his life started does not meet this objection. It would not be reasonable for the Robsonian to suggest that the person's prenatal nonexistence is not bad for him precisely because it was not bad for him while it was going on. To begin with, on Robson's view, the reason that the person's prenatal nonexistence was not bad for him during that period is simply that he did not exist in any form then. This reason evidently does not apply once the person does exist in some form. Furthermore, it cannot hold in general on Robson's view that if something that occurred or obtained in the past is bad for a person, then it was bad for him already when it occurred or obtained. Consider an event that occurred prior to a currently living person's lifetime, and because of which the person is much worse off overall than he would have otherwise been, and which did not affect when his life began. This event is bad for the person, but on Robson's view it was not bad for him when it occurred, as he did not exist then.

At this point it might instead be suggested that everything that is bad for a person makes him worse off at some time than he would have otherwise been at that time. Because, on the growing block view, a person does not exist in any form before his life begins, he does not occupy any well-being level then, and thus is not worse off then. By contrast, a dead person exists simpliciter and can therefore be worse off while dead (presumably by occupying a well-being level of zero while dead). However, both the claim that everything that is bad for a person makes him worse off at some time, and the claim that death satisfies that condition, are highly contested (Broome 2013; Bykvist 2015; Johansson 2012, 2014c). It would not be a good strategy for the Robsonian to rely on them here.

So far, I have argued that Robson's approach does not support the claim that a person's prenatal nonexistence is not bad for him. This point needs to be modified. For of course, if an individual's life has not yet begun, then Robson's approach does rule out that his prenatal nonexistence is bad for him. This does not help the

\footnotetext{
5 Different theorists may disagree on whether the "is" in these claims should, or should not, be given an "atemporal" reading. This makes no difference to the present points.
} 
deprivationist, however, because Robson's approach also rules out that such an individual's death is bad for him-for the simple reason that it rules that anything at all is bad for him. Thus, Robson's approach prevents the deprivationist from saying that a future person's death, unlike his prenatal nonexistence, is bad for him.

In fact, Robson's approach, aside from giving the deprivationist no reason to deny that prenatal nonexistence is bad for a currently or formerly living person, appears to rule out that a currently living person's death is bad for him. For at least assuming that we conceive of a person's death as a concrete event-which is customary in the literature on death's evil-it simply does not exist before it occurs, on the growing block view. Not only has it not yet taken place, it does not exist in any form at all. Further, just as a person apparently needs to exist, in some form or another, in order for an event to be bad for him, surely the event, too, needs to exist in some form or another: a non-existent entity cannot be bad for anyone. On the present view, then, the event of death is not bad for a currently living person. That is, not only is its badness not located at the present moment; it is not bad for him in any way at all. By contrast, if an event ensures that a person's life begins later than it would have otherwise done, nothing in the growing block view prevents this event from being bad for the person once he is alive. This is not the sort of asymmetry that the deprivationist wants.

Acknowledgments For helpful comments I am grateful to anonymous refereees and to the audience at the International Association for the Philosophy of Death and Dying conference at Syracuse University in May 2016.

Open Access This article is distributed under the terms of the Creative Commons Attribution 4.0 International License (http://creativecommons.org/licenses/by/4.0/), which permits unrestricted use, distribution, and reproduction in any medium, provided you give appropriate credit to the original author(s) and the source, provide a link to the Creative Commons license, and indicate if changes were made.

\section{References}

Bradley, B. 2009. Well-being and death. Oxford: Oxford UP.

Broome, J. 2013. The badness of death and the goodness of life. In The Oxford handbook of philosophy of death, ed. B. Bradley, F. Feldman, and J. Johansson, 218-233. New York: Oxford UP.

Brueckner, A.L., and J.M. Fischer. 1986. Why is death bad? Philosophical Studies 50: 213-223.

Bykvist, K. 2015. Value and time. In The Oxford handbook of value theory, ed. I. Hirose, and J. Olson, 117-135. New York: Oxford UP.

Cyr, T. 2014. Rationally not caring about torture: A reply to Johansson. The Journal of Ethics 18: 331-339.

Cyr, T. 2016. Death's badness and time-relativity: A reply to Purves. The Journal of Ethics 20: 435-444. Deng, N. 2012. Fine's McTaggart, temporal passage, and the A versus B-debate. Ratio 26: 19-34.

Deng, N. 2015. How A-theoretic deprivationists should respond to Lucretius. Journal of the American Philosophical Association 1: 417-432.

Epicurus, B. 1940. Letter to Menoeceus. In The stoic and epicurean philosophers, ed. W.J. Oates. New York: The Modern Library.

Feit, N. 2016. Comparative harm, creation and death. Utilitas 28: 136-163.

Feldman, F. 1991. Some puzzles about the evil of death. Philosophical Review 100: 205-227.

Feldman, F. 2013. Brueckner and Fischer on the evil of death. Philosophical Studies 162: 309-317. 
Fischer, J.M., and A.L Brueckner. 2013. The evil of death and the Lucretian symmetry: a reply to Feldman. Philosophical Studies 163: 783-789.

Fischer, J.M., and A.L. Brueckner. 2014a. Prenatal and posthumous non-existence: A reply to Johansson. The Journal of Ethics 18: 1-9.

Fischer, J.M., and A.L. Brueckner. 2014b. Accommodating counterfactual attitudes: A further reply to Johansson. The Journal of Ethics 18: 19-21.

Fischer, J.M., and A.L. Brueckner. 2014c. The mirror-image argument: An additional reply to Johansson. The Journal of Ethics 18: 325-330.

Johansson, J. 2012. The timing problem. In Oxford handbook of philosophy and death, eds. B. Bradley, F. Feldman, and J. Johansson, 255-273. Oxford: Oxford University Press.

Johansson, J. 2013. Past and future non-existence. The Journal of Ethics 17: 51-64.

Johansson, J. 2014a. Actual and counterfactual attitudes: reply to Brueckner and Fischer. The Journal of Ethics 18: 11-18.

Johansson, J. 2014b. More on the mirror: reply to Fischer and Brueckner. The Journal of Ethics 18: 341-351.

Johansson, J. 2014c. When do we incur mortal harm? In The Cambridge companion to life and death, ed. S. Luper, 149-164. Cambridge: Cambridge University Press.

Johansson, J. 2016. Asymmetry and incoherence: a reply to Cyr. The Journal of Ethics. doi:10.1007/ s10892-016-9238-5

Le Poidevin, R. 1996. Arguing for atheism. London: Routledge.

Lucretius, T.C. 1940. On the nature of things. In The stoic and epicurean philosophers, ed. W.J. Oates, 69-219. New York: The Modern Library.

Luper, S. 2009. The philosophy of death. Cambridge: Cambridge University Press.

Purves, D. 2015. Torture and incoherence: A reply to Cyr. The Journal of Ethics 19: 213-218.

Robson, J. 2014. A-time to die: A growing block account of the evil of death. Philosophia 42: 911-925. 